\title{
Overview of Epidemiological Investigations: Nurses' Role
}

\author{
Amala Seeli \\ Assistant Professor, Pragyan College of Nursing, Bhopal, Madhya Pradesh, India. \\ DOI: https://doi.org/10.24321/2348.2133.202001
}

$\begin{array}{llll}\text { I } & \mathbf{N} & \mathbf{F} & \mathbf{O}\end{array}$

E-mail Id:

amalaseeli90@gmail.com

Orcid Id:

https://orcid.org/0000-0001-9485-5939

How to cite this article:

Seeli A. Overview of Epidemiological Investigations:

Nurses' Role. Ind J Holist Nurs 2020; 11(3): 1-5.

Date of Submission: 2020-11-21

Date of Acceptance: 2020-12-31

\section{$\begin{array}{llllllll}\mathbf{A} & \mathbf{B} & \mathbf{S} & \mathbf{T} & \mathbf{R} & \mathbf{A} & \mathbf{C} & \mathbf{T}\end{array}$}

Emerging infectious diseases continue to disrupt the health care system in each level and are becoming progressively complicated to detect and treat successfully. Epidemiological investigations are a challenging task for the Health workers. The main purpose of this investigation is to identify the disease in the early stage and reduce the number death due to the sudden outbreak of any communicable diseases in the community. The steps in outbreak investigation should be "quick and clean." Investigating an outbreak requires a combination of diplomacy, logical thinking, problem-solving ability, quantitative skills, and judgment. These skills improve with practice and experience.

Keywords: Epidemiological Investigation, Communicable Diseases, Outbreak, Quantitative Skills

\section{Introduction}

Epidemiology began with Adam and Eve both trying to investigate the qualities of the "forbidden fruit." The term epidemiology is derived from the Greek word. The term epidemiology is derived from the Greek word epidemic.

Epi means Among, upon,

Demos - study population or people

Logos -scientific study

Epidemiology is the study of the frequency, distributions and determinants of health-related states or events in specified population and the application of this study to control health problems.

Epidemiology and Community health are two inseparable words in public health system. This is because they deal with prevention of disease, promotion of health and efficiency through organized community efforts. Epidemiology deals with the frequencies and types of illnesses and injuries that affect population while community health deals with the services that aim at protecting the health of the community. ${ }^{1}$

\section{History of Epidemiology}

The history of epidemiology has its origin in the idea, goes back to (400BC) The Greek physician.

Hippocrates, known as the father of medicine, sought a logic to sickness; he is the first person known to have examined the relationships between the occurrence of disease and environmental influences.

John Snow is famous for his investigations into the causes of the 19th-century cholera epidemics, and is also known as the father of (modern) epidemiology. He began with noticing the significantly higher death rates in two areas supplied by Southwark Company. His identification of the Broad Street pump as the cause of the Soho epidemic is considered the classic example of epidemiology. Snow used chlorine in an attempt to clean the water and removed the handle; this ended the outbreak. This has been perceived as a major event in the history of public health and regarded as the founding event of the science of epidemiology, having helped shape public health policies around the world. ${ }^{2}$ 
Other pioneer in epidemiology was Peter Anton Schleisner, who in 1849 related his work on the prevention of the epidemic of neonatal tetanus. In the year 1865, British surgeon Joseph Lister discovered antiseptics whereas Ronald Ross, Janet Lane-Claypon, Anderson Gray McKendrick, and others introduced mathematical methods into epidemiology by $20^{\text {th }}$ century.

Epidemiology has grown rapidly during the past decades. It has now firmly established in Nursing education. It is necessary that every nurse should have essential knowledge about epidemiological knowledge for immediate control of disease.

\section{Uses of Epidemiology}

- Study the occurrence and distribution of diseases in a community. ${ }^{3}$

- Identify the determinants of diseases.

- Diagnose the health status of the community

- Estimate the risk

- Plan effective need-based health care services

- Determine the effectiveness of health care services planned.

- Determine the usefulness and effectiveness of new/ innovative techniques, measures and programmes

- Complete the clinical picture of chronic diseases arid slow growing diseases.

- Identify syndromes by describing the distribution and association of clinical phenomena in the population.

- Forecast the likely occurrence of diseases on the basis of epidemiological principles.

\section{Theories and Models of Disease Causation}

\section{Supernatural Theory}

This theory says that disease occur due to super powers, for example, gods, evil, spirit, disease and human sufferings and calamities were attributed to the wrath of god, influence of evil spirits, stars \& planets (Figure 1 ). ${ }^{4}$

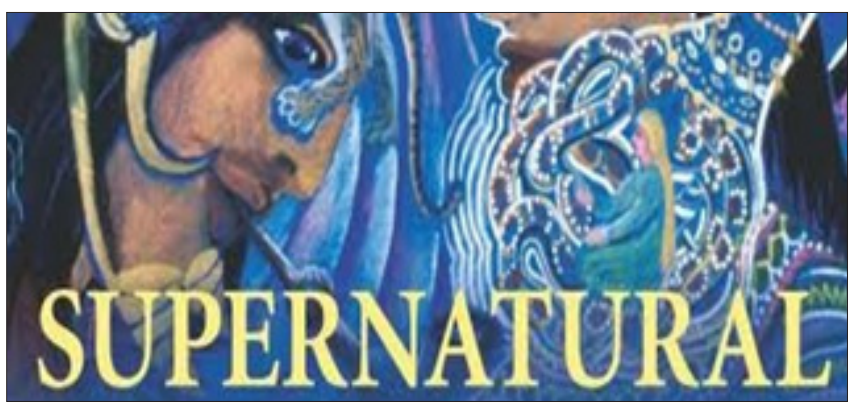

Figure I.Supernatural Theory

\section{The Germ Theory}

According to this theory, there is one single specific cause of every disease. This refers to one to one relationship between the causative agent and disease (Figure 2). ${ }^{5}$

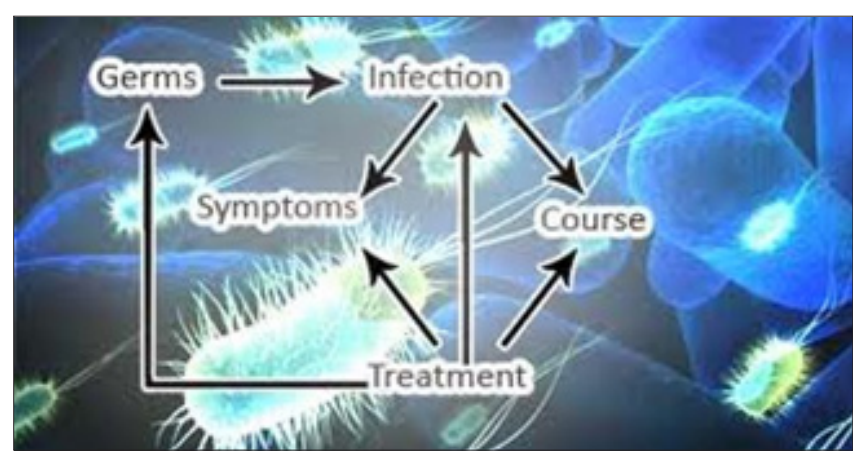

Figure 2.Germ Theory

\section{Theory of Epidemiological Triad}

According to this theory, every one exposed to disease agent did not contract the disease. This means it is not only the causative agent that is responsible for disease but there are other factors also, related to man and environment which contribute to disease (Figure 3 ).

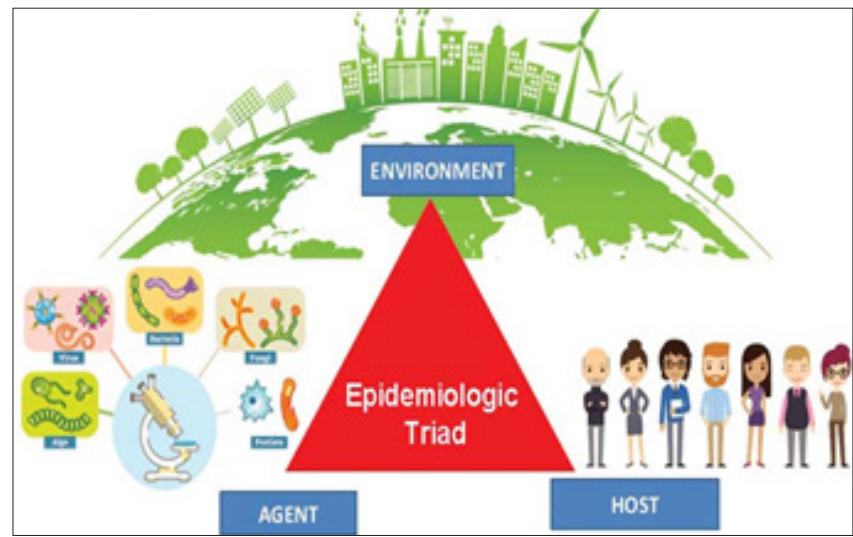

Figure 3.Epidemiological Triad Multifactorial Causation Theory

Epidemiological theory is not applicable for non-infectious and chronic diseases like coronary artery diseases etc. because it has many causes or multiple factors. ${ }^{6}$

This theory helps to understand the various associated causative factors, prioitise and plan preventive and plan measures to control the disease (Figure 4).

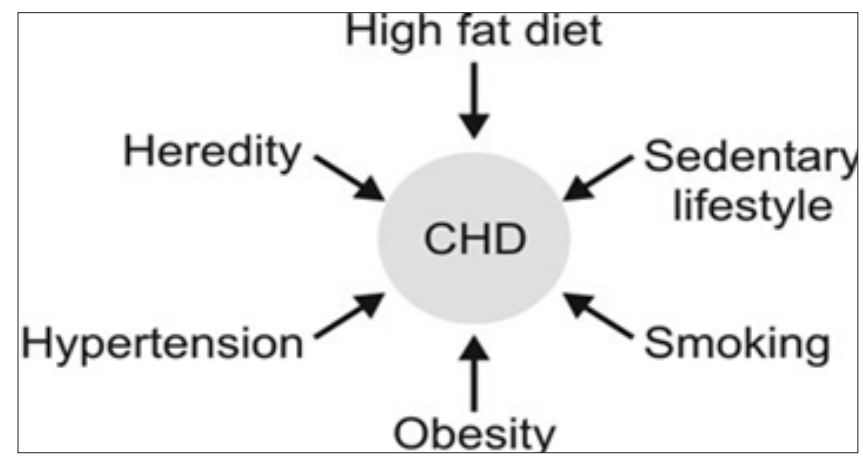

Figure 4.Multifactorial causation theory 


\section{Web of Causation}

According to macmohan and pugh diseases never depends upon a single isolated factor perhaps it develops from a chain of causation. There will be a complex interaction between chain of causation which may be the fraction of the whole complex is known as web of causation (Figure 5).

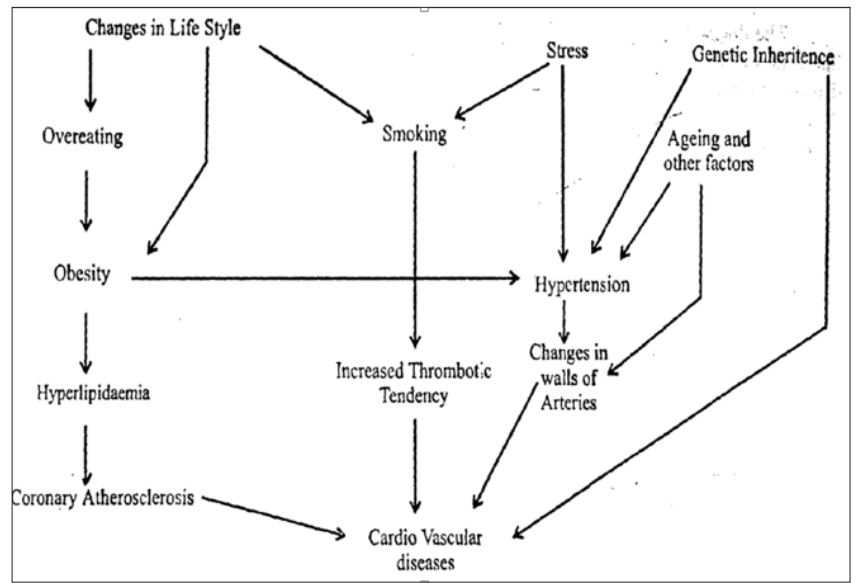

Figure 5.Web of Causation

\section{Epidemiological Methods}

\section{Observational Studies}

\section{Descriptive Studies}

Descriptive method of epidemiological study is concerned with the study of frequency and distribution of disease and health related events in population in terms of person, place and time. $^{7}$

There are two different designs to conduct descriptive studies in epidemiology:

- Cross-sectional studies

- Longitudinal Studies

\section{Analytical Studies}

The object is not to formulate hypothesis but to test hypothesis.

It contains two types:

- Case control study

- Cohort study

\section{Experimental Studies}

- Randomized control trials

- Field trials

- Community trials

\section{Steps in Epidemiological Investigation Verification of Diagnosis}

This is the First step in the investigation. The public or health worker may be spurious due to misinterpretation of signs and symptoms. In order to conform the diagnosis it is not necessary to examine all cases. laboratory investigation as well as clinical examination of sample cases is sufficient to confirm the diagnosis laboratory investigation should be done in applicable areas will be more helpful to confirm the disease. As soon a disease outbreak is notified control measures should be initiated in the community it should not be delayed for the laboratory results. ${ }^{4}$

\section{Nurses Role}

Obtain their medical records and laboratory records clearly while we verifying the diagnosis the Nurses will be often confused between food poisoning, cholera and gastroenteritis.

All continuous fever cases may not be typhoid fever even with epidemic of typhoid fever.

At the same time occurrence of different conditions can also be confusing for the investigator. A complete review of laboratory records and a extensive study of the samples is very essential to confirm the diagnosis .

\section{Confirmation of the Existence of an Epidemic}

Done by comparing the number of cases with disease frequencies during the same period of previous years.

\section{Nurses Role}

Nurses monitor any increase in number of cases. In case of endemic diseases like cholera, typhoid hepatitis A, it is expected that some cases (few hundreds) always present throughout the year. So, the diseases to be considered as epidemic, several hundreds or thousands of cases have to occur in India.

In case of yellow fever, bubonic plague and polio even a single case will constitute an epidemic; in India, information may be collected from routine health service records e.g. OPD registers, in-patient registers etc. Information should be collected not only from modern medicine practitioners but also from other systems States or districts should establish criteria on the number of cases that constitute an epidemic based on their local situation. Public health nurse should start collecting the information from her community and coordinate with ASHA and other health workers to confirm any existence of outbreak in your locality

\section{Defining the Population at Risk}

Obtaining the Map of the Area

While obtaining the information about the area, the map should include information about natural landmarks (river, mountains), roads and location of all dwelling units along each road. Each area feasibly split up into segments using natural landmarks as boundaries. This is again cut up into smaller sections. In each section, the dwelling units may be deputed by numbers for easy identification. 


\section{Counting the Population}

By doing census by house to house visits. The composition should be known by age and sex.

\section{Nurses Role}

Having a good knowledge about the community area and its boundries will help a nurse identify the population at risk, easily isolate them from others. For example, in case of food poisoning - those who ate the food. In case of outbreak of cholera-those who were using water from the suspected well.

\section{Rapid Search for all Cases and their Characteristics}

\section{Surveillance}

It is the ongoing systemic collection, analysis and interpretation of health data. In order to get timely dissemination of information to those who need to know so that necessary action can be taken to prevent the diseases.

- Individual Surveillance

- Local population surveillance, e.g., surveillance of malaria

- National population surveillance, e.g., surveillance of smallpox after the disease has been eradicated

- International surveillance,e.g., influenza, malaria, polio, cholera etc are the important diseases listed under WHO, for the timely warning to all the national governments

\section{Epidemiological Case Sheet}

This should be carefully designed to collect relevant information. If the epidemic is large, it may not be possible to examine all the cases. In such cases random sample should be examined. ${ }^{8}$

\section{Nurses Role}

Coordinate and train the health workers about how to obtain the basic information; interview the cases; review the surveillance data.

Prepare a case sheet that includes name, age, sex, occupation, social class, travel history, signs and symptoms of illness, personal contacts and inform Central/ District Disease Surveillance Unit.

\section{Data Analysis}

The data collected should be analyzed by using the parameters: Time, Place and Person.

\section{Time}

Prepare a chronological distribution of dates of onset of cases and construct an "epidemic curve."

\section{Nurses Role}

While preparing an epidemic curve note:
- Pattern of spread

- Magnitude

- Outliers

- Exposure and/ or disease incubation period

Place

Prepare a 'spot map' of cases and if possible, their relation to the sources of infection

\section{Nurses Role}

While spotting map the sources infection areas like water supply, air pollution, foods eaten, occupation etc should be noted. Prepare a map that shows the boundaries and patterns of disease distribution. Clustering of cases indicates a common source of infection.

\section{Person}

Analyze the data by age, sex, occupation and other possible risk factors. ${ }^{9}$

\section{Nurses Role}

Identity the person, type of illness like acute or chronic illness. Determine the attack rates/ case fatality rates. Prepare a data analysis which helps you to:

- To determine modes of transmission and the source and the vehicle of the agent, so that the most effective measures can be initiated.

- To determine the risk factors for disease.

\section{Formulation of Hypothesis}

The hypothesis should explain the epidemic in terms of:

- Causative agent

- The possible source

- Possible modes of spread

- The environmental factors which enabled it to occur.

Nurses Role

Hypothesis should be compared between the exposed group along with the non-exposed group to each of the suspected factor. Occasionally the Nurse can also analytical study design (case control study) to test the hypothesis for the statistical significance.

\section{Evaluation of Ecological Factors}

The ecological factors which have made the epidemic possible should be investigated.

\section{Nurses Role}

In the event of water borne diseases, a vast survey of sanitation in the water supply system is needed. Investigation from the source to consumer should be done.

Needed to obtain further information. This may involve medical examination, screening tests, examination of suspected food, faces or food samples, biochemical 
studies, assessment of immunity status etc. This will permit classification of all members regarding:

- Exposure to specific potential vehicles

- Whether ill or not

\section{Writing a Report}

The report should be complete and convincing. The information to be included in the final report is: ${ }^{10}$

Background: Geographical location, Climatic conditions, Demographic status (population pyramid), Socioeconomic situation, Organization of health services, Surveillance and early warning systems, Normal disease prevalence.

Historical Data: Previous occurrence of epidemics- of the same disease, - locally or elsewhere, Occurrence of similar diseases - in the same area, - in other areas Discovery of the first cases of the present outbreak.

Methodology of Investigations: Case definition, Questionnaire used in epidemiological investigation, Survey teams, Household survey, Collection of laboratory specimens, Laboratory techniques.

Analysis of Data: Clinical data - frequency of signs and symptoms, course of disease, differential diagnosis, sequelae or death rates, epidemiological data, mode of occurrence - In time, By place, By population groups; Modes of transmission - sources of infection, routes of excretion and portal of entry, factors influencing transmission; laboratory data isolation of agents, serological confirmation, significance of results Interpretation of data, comprehensive picture of the outbreak; hypothesis as to the causes, formulation and testing of hypothesis by statistical analysis.

Control Measures: Definition of the strategies and methodology of implementation - constraints, results; evaluation - significance of results, cost/effectiveness; preventive measures.

It may be necessary to implement temporary control measures at the commencement of an epidemic on the basis of known facts of the disease. These measures may be modified or replaced in the light of new knowledge acquired by the epidemic investigation.

\section{Conclusion}

A well planned collaboration with all health team members including mass media and people is needed during an investigation. The information which is given to the public should be trust worthy so that it won't create any unnecessary confusion among the public.

Nurses updated knowledge in epidemiological investigation will prevent community during emergency situation and have immediate control of disease. Sometimes investigation is done after the epidemic has burnt out or disease has resumed endemic level.
Nurses are the front line workers in battling during the outbreak situation. we play a very important role locally as well as globally.

Educating the public, preparedness for a emergency response, breaking the chain of transmission in the community should be the main focus in handling health crisis

\section{Conflict of Interest: None}

\section{References}

1. Text Book of Preventive and social medicine: Banarsidas Bhanot Pvt., Ltd. 2012.

2. Last JM, editor. Dictionary of epidemiology. 4th ed. New York: Oxford University Press; 2001; 61.

3. Greenwood M. Epidemics and crowd-diseases: an introduction to the study of epidemiology, Oxford University Press; 1935.

4. Hacker SB. Historical development. In: Teutsch SM, Churchill RE, editors. Principles and practice of public health surveillance, 2nd ed. New York: Oxford University Press; 2002; 1-16.

5. Snow J. Snow on cholera. London: Humphrey Milford: Oxford University Press; 1936.

6. Doll R, Hill AB. Smoking and carcinoma of the lung. Brit Med J 1950; 2: 739-748.

7. Kannel WB. The Framingham Study: its 50-year legacy and future promise. J Atheroscler Thromb 2000; 6: 60-66.

8. Fenner F, Henderson DA, Arita I, Jezek Z, Ladnyi ID. Smallpox and its eradication. Geneva: World Health Organization; 1988.

9. Morris JN. Uses of Epidemiology. $3^{\text {rd }}$ Edition, Edinburgh: Churchill Livingstone, 1975.

10. Norell SE. Workbook of Epidemiology. New York: Oxford University Press, 1995. 